\title{
Nutrient Analysis Critical Control Point (NACCP): Hazelnut as a Prototype of Nutrigenomic Study
}

\author{
Laura Di Renzo ${ }^{*}$, Alberto Carraro ${ }^{1}$, Daniela Minella $^{1}$, Roberto Botta $^{2}$, Cecilia Contessa ${ }^{2}$, \\ Chiara Sartor ${ }^{2}$, Anna Maria Iacopino ${ }^{3}$, Antonino De Lorenzo ${ }^{1,4}$ \\ ${ }^{1}$ Section of Section of Clinical Nutrition and Nutrigenomic, Department of Biomedicine and Prevention, University of Rome "Tor
Vergata”, Roma, Italy; ${ }^{2}$ Department of Agricultural, Forest and Food Sciences (DISAFA), University of Turin, Grugliasco, Italy;
${ }^{3}$ Department of Agricultural Sciences, University of Reggio Calabria "Mediterranea”, Reggio Calabria, Italy; ${ }^{4}$ I.N.DI.M. National
Institute for Mediterranean Diet and Nutrigenomics, Amantea, Italy. \\ Email: "laura.di.renzo@uniroma2.it
}

Received October 31 $1^{\text {st }}, 2013$; revised November $30^{\text {th }}, 2013$; accepted December $7^{\text {th }}, 2013$

Copyright (c) 2014 Laura Di Renzo et al. This is an open access article distributed under the Creative Commons Attribution License, which permits unrestricted use, distribution, and reproduction in any medium, provided the original work is properly cited. In accordance of the Creative Commons Attribution License all Copyrights (C) 2014 are reserved for SCIRP and the owner of the intellectual property Laura Di Renzo et al. All Copyright (C) 2014 are guarded by law and by SCIRP as a guardian.

\section{ABSTRACT}

The aim of this study is to apply the Nutrient Analysis Critical Control Point (NACCP) process to ensure that the highest nutrient levels in food can determine a beneficial effect on the health of the consumer. The NACCP process involves a sequence of analysis and controls that depart from raw material production to the evaluation of the effect of nutrition on health. It is articulated through the following points: 1) identification of nutrient level in the food; 2) identification of critical control points (environmental, genetic data, chemical and physical data, production technology, distribution and administration); 3) establishing critical limits that can impoverish and damage the nutrient; 4) establishing measures to monitor; 5) establishing corrective actions. We selected as biomarkers the total phenolic content (TPC) and total antioxidant capacity (TAC) of a genotyped Italian hazelnut cultivars (Corylus e avellana L.). We performed a clinical study evaluating: a) nutritional status; b) clinical-biochemical parameters; c) low density lipoprotein oxidation (LDL-ox); d) the expression level changes of oxidative stress pathway genes in the blood cell at baseline and after $40 \mathrm{~g} / \mathrm{die}$ of hazelnut consumption. In this study, we found a significant lowering ( $\leq 0.005)$ of LDL oxidized proteins, in association with the consumption of $40 \mathrm{~g} / \mathrm{d}$ of hazelnuts. Also, we found a significant variation $(p \leq 0.005)$ of gene expression of antioxidant and pro-oxidant genes, between the intake of dietary with and without hazelnuts. This results support the hypothesis that the NACCP process could be applied to obtain significant benefits in terms of primary prevention and for contributing to the amelioration of food management at the consumer level.

\section{KEYWORDS}

\section{NACCP Process; Hazelnut; Nutrigenomic; Oxidative Stress; LDL-Oxidation}

\section{Introduction}

The globalization of trade has increased the chances that the food produced in one place can affect the health and diet of people living in another. The rapid increase of knowledge on nutrition, medicine and plant biotechnology has dramatically changed the concepts about food. This problem has led to an increased incidence of diabetes, obesity, different cancer and vascular disease,

*Corresponding author. physiological problems, as well as other degenerative diseases [1]. In the post-genomics era, food is not only considered as a reservoir of macronutrients, which serve to maintain cellular metabolism, but becomes essential to be able to differentiate a good or bad state of health. In fact, the close relationship that exists between microntrients and gene expression may underlie the pathophysiologic phenomena or, in the reverse case, it may become the first way to slow the onset of chronic degenerative diseases. The aim of this study is to apply the Nutrient 
Analysis Critical Control Point (NACCP) process to ensure that the highest nutrient levels in food can determine a beneficial effect on the health of the consumer. The goal of NACCP is to identify a biomarker as an indicator of the nutritional quality of food. To apply the NACCP process we selected as biomarker the total phenolic content (TPC) and total antioxidant capacity (TAC) of genotyped Italian hazelnut cultivars (manca spazio (Corylus avellana) L.). We focused our attention on hazelnuts, as they are rich source of unsaturated fatty acids, L-arginine, antioxidants, phytochemicals and because it is known that regular nuts consumption may reduce the risk of heart disease and other chronic diseases. In particular, hazelnuts have a significant place among the dried nuts in terms of nutrition and health owing to their special composition of fats, protein, carbohydrates, vitamins, minerals, dietary fibers and phenolic antioxidants [2]. The nutritional and sensory properties of hazelnuts make them a unique and ideal raw material for food products [3]. To apply the NACCP process we made a clinical study to verify the anti-atherogenic effect of the consumption of hazelnuts on low density lipoprotein (LDL), evaluating the susceptibility of these molecules to oxidation (LDL-ox). Furthermore, we analyzed the expression level changes of oxidative stress pathway genes in the blood cell after hazelnuts consumption.

\section{Materials and Methods}

\subsection{NACCP Process}

The NACCP process involves a sequence of analysis and controls that depart from raw material production to the evaluation of the effect of nutrition on health. It is articulated through the following points: 1) identification of nutrient level in the food; 2) identification of critical control points (environmental, genetic data, chemical and physical data, production technology, distribution and administration); 3) establishing critical limits that can impoverish and damage the nutrient; 4) establish measures to monitor; 5) establishing manca spazio (corrective actions). The actions of NACCP are: 1) enviromental, agronomic, zootechnical analyses; analysis of the nutrients (study of the nutraceutical properties); 2) identification of natural biomarkers; 3) shelf life; 4) definition of cooking modes; 5) study of the effect of the nutrient on the consumer; 6) identification of biomarker in humans; 7) health claims [4]. In the present work, the NACCP process was applied to the hazelnut food chain, according to the following steps: 1) Chemical and physical analyses; 2) DNA typing of the hazelnut sample; 3) clinical trials.

\subsection{Chemical and Genetic Analysis}

\subsubsection{Samples Preparation}

The analyses were carried out on the Italian hazelnut cultivar “Tonda Gentile delle Langhe” (TGL, syn. "Tonda Gentile Trilobata”) harvested in a single orchard in Piedmont. In-shell hazelnuts were stored at $4^{\circ} \mathrm{C}$ until analysis.

\subsubsection{Protein, Total Lipid and Moisture Content}

Protein content of hazelnuts was obtained by mineralization in sulfuric acid, steam distillation, acid-base titration. The hazelnut total lipid content was measured using the analytic technique of solvent extraction according to protocol of Ref. [5]. The hazelnut moisture content was calculated by gravimetry according to protocol of Ref. [6].

\subsubsection{Total Phenolic Content (TPC) and Total Antioxidant Capacity (TAC)}

The amount of total phenolics in triplicate kernel extracts was measured following the Folin-Ciocalteu procedure, the method of Slinkard and Singleton [7], using gallic acid as standard. Total antioxidant capacity was determined using the FRAP (Ferric Reducing Antioxidant Power) assay, according to Benzie and Strain method [8], modified by Pellegrini et al. [9].

\subsubsection{DNA Typing of the Hazelnut Sample}

Hazelnuts were genotyped by analyzing the DNA obtained from the perisperm, a maternal tissue. The extraction was performed as described in Doyle and Doyle [10] with minor modifications. A total of eight hazelnut SSR loci fully characterized were used: CaT-B107 (FP: GTAGGTGCACTTGATGTGCTTTAC, RP: AACACATATTGA

TCTTTCAAAGC) CaT-B501 (FP: GAAATTCA ATCACACCAATAAAGCA, RP: CCTCCCTTG TCCTCATCACTG), CaT-B502 (FP: CTCATGA CTGCCCATTTCTCG, RP: AGGCATGCAGGC TTCACAC), CaT-B504 (FP: CGCCATCTCCAT TTCCCAAC, RP: CGGAATGGTTTTCTGCTTCAG), CaT-B505 (FP: AGAGAACGACTTTGTA TGACAAGA, RP: TTGAACATTAAATACATC ATGTGA), CaT-B507 (FP: CTAGCTCACAGA GGAAGTGAT, RP: GCTTCTGGGTCTCCTGCTCA), CaT-B508 (FP: GGGTCAAGATTGTAAA GTGGGA, RP: GCACTCCATGTGCGTTTTC) [11] and CaC-B028 (FP: ATGGAGAGGTATTT

CAGC, RP: CCTGTTTCTCTTTGTTTTCGAG) [12]. PCR was performed as described by Boccacci et al. [13]. PCR products were analyzed on a 3130 Genetic Analyzer (Applied Biosystems, Foster City, CA, USA). Data were processed using Gene Mapper Software (ver. 4.0; Applied Biosystems, Foster City, CA, USA) and alleles were defined by their size in base pairs, by comparison with the standard size (GeneScan-500 LIZ, Applied Biosystems, Foster City, CA, USA). 
Table 1. Comparison of nutritional indices between Standard Diet and Standard Diet plus $40 \mathrm{~g} / \mathrm{die}$ of hazelnut supplementation.

\begin{tabular}{cccc}
\hline & Standard Diet & $\begin{array}{c}\text { Standard Diet with } \\
\text { 40 g/d hazelnut }\end{array}$ & p-value \\
\hline RMR (kcal) & $1056.69 \pm 75.68$ & $1318.68 \pm 62.24$ & \\
RMR (Kjoule) & $4423.31 \pm 50.85$ & $5520 \pm 25.24$ & \\
P (g) & $48.97 \pm 15.21$ & $54.49 \pm 20.35$ & a \\
C (g) & $143.03 \pm 23.46$ & $145.47 \pm 29.36$ & b \\
L (g) & $36.05 \pm 26.51$ & $61.69 \pm 27.32$ & a \\
AI & $0.20 \pm 0.5$ & $0.17 \pm 0.7$ & a \\
TI & $0.41 \pm 1.2$ & $0.32 \pm 1.6$ & a \\
\hline
\end{tabular}

RMR = Resting metabolic rate. $\mathrm{P}^{\mathrm{a}}=$ protein. $\mathrm{C}^{\mathrm{b}}=$ carbohydrates. $\mathrm{L}^{\mathrm{a}}=$ lipids. $\mathrm{AI}^{\mathrm{a}}=$ Atherogenic Index. $\mathrm{TI}^{\mathrm{b}}=$ Thrombogenicity Index. Values are expressed as mean \pm standard deviation and maximum and minimum value detected. The significant values are expressed as: (a) $\mathrm{p}<0.05$ and (b) $\mathrm{p}>$ 0.05 .

\subsection{Clinical Trials}

\subsubsection{Partecipants and Study Design}

A total of 30 participants were recruited by Clinical Nutrition and Nutrigenomic Section of University of Rome Tor Vergata. To be eligible for the study, participants had to meet the inclusion criteria: they had to be aged between 18 and 50 years, with a $\mathrm{BMI} \geq 19 \mathrm{Kg} / \mathrm{m}^{2}$. The exclusion criteria were: hepatitis, autoimmune, cardiovascular and metabolic diseases. All participants will be required to provide written informed consent for the study. The experimental design follows the phases of the process NACCP. The study was carried out with a crossover design as follow: a) standard diet (SD) for 4 weeks; b) wash out period for 3 weeks; c) SD with 40 g daily (g/d) of hazelnuts. Compliance was assessed by 3-d diet records (3DDRs) completed during the study.

Trial Registration: This protocol has been registrated by ClinicalTrials.gov ID: NCT01890070.

\subsubsection{Clinical Visit and Nutritional Status}

At baseline, all participants were subjected to evaluation of health status. The assessment of nutritional status was analyzed by anthropometry and bioelectrical impedance analysis. According to standard methods (body weight, height, hip and waist circumferences), body weight ( $\mathrm{kg}$ ), waist and hip measures were taken according standard protocol. Body mass index (BMI) was calculated using the formula: $\mathrm{BMI}=$ body weight $/$ height ${ }^{2}\left(\mathrm{~kg} / \mathrm{m}^{2}\right)$. Bioelectrical impedance analysis was conducted according standard protocol with the software provided by the manufacturer [14-16].

\subsubsection{Dietary Assessment and Nutritional Intervention}

Standard diet refers to an Italian Mediterranean Diet (IMOD). The dietary pattern of each subject was eva- luated by nutritional indices: Atherogenic Index (AI), Thrombogenic Index (TI) $[17,18]$. No alcoholic beverages were allowed on gender by a software DIETO-SYS$\mathrm{TEM}^{\circledR}$. The alimentary diary and nutrient intake were analysed using diet analyser software DIETOSYSTEM ${ }^{\circledR}$.

\subsubsection{Sample Collection and RNA Extraction}

Fasted blood sample was collected and stabilized in PAXgene Blood RNA Tubes (PreAnalyti (PreAnalytiX Qiagen), Hombrechtikon, Switzerland), and stored at $-80^{\circ} \mathrm{C}$ until the RNA extraction. Total RNA of each collected sample was purified using the PAXgene Blood miRNA Kit according to the manufacturer's instructions (PreAnalytixQiagen, Hombrechtikon, Switzerland). Aliquots of total RNA were then quantified and assessed for quality by spectrophotometry (Nanodrop, Wilmington, USA) and agarose gel electrophoresis.

2.3.5. Quantitative Real Time PCR and Data Analysis We used a specific $\mathrm{RT}^{2}$ Profiler PCR Arrays (Qiagen, Netherlands): for our study we focused our attention on Human Oxidative Stress (PAHS-065ZA, Qiagen, Netherlands) pathway. Each qRT-PCR experiment was performed in triplicate and repeated at least twice, according to manifacturer's instruction (Qiagen, Netherlands). The value used to plot relative gene expression was determined using the expression Fold Change $(\mathrm{FC})=2^{-\Delta \Delta \mathrm{CT}}$ [19], as shown in Figure 1. Raw data were filtered for genes that were significantly changed above factor 1.0 within the $95 \%$ confidence interval $(p \leq 0.05)$ for each experiment. Finally, only genes with an absolute FC value of at least \pm 1.5 and $p$-value $\leq 0.05$ were considered as differentially expressed genes.

\subsubsection{Oxidative Status}

Blood samples were collected and stabilized in EDTA. The study of the level of oxidation of the organism has been studied through the quantification of the protein and oxidized LDL from the nutrigenomic study. For the study of LDL was used in the ELISA test Mercodia Oxidized LDL ELISA (Mercodia Diagnostic, Sweden), according to customer protocol.

\subsubsection{Statistical Analysis}

A paired t-test or a non-parametric (Wilcoxon test) were performed to evaluate differences before and after nutriational intervention. All tests were considered significant at $\mathrm{p} \leq 0.05$. Statistical analysis was performed using a computer software package SAS version 9.3 (SAS Institute, Cary, NC).

\section{Results}

\subsection{Chemical and Geneticanalyses}

Chemical and antioxidant capacity analyses were carried 


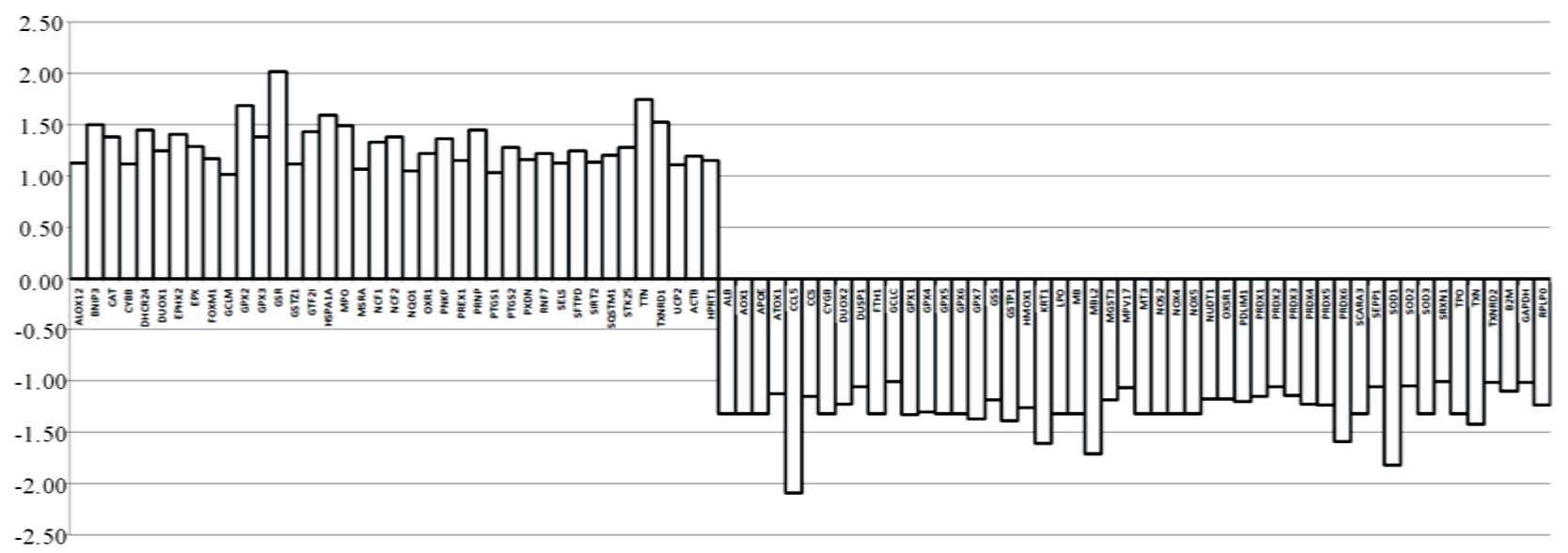

Figure 1. Flow diagram of the study. CONSORT diagram of the study.

out on samples of $100 \mathrm{~g}$ of TGL hazelnuts. On dry weigth, the protein content was $12.9 \%( \pm 2.5)$; the total fat content was $54.4 \%( \pm 1.1)$ and the moisture content was $2.9 \%$ $( \pm 0.3)$. The hazelnut kernel had a total phenolic content of GAE $1.02 \pm 0.01 \mathrm{~g} \cdot \mathrm{kg}^{-1}$ and showed a total antioxidant capacity (FRAP) of $7.88 \pm 0.43 \mathrm{mmol} \mathrm{Fe} \mathrm{F}^{2+} / \mathrm{kg}$, in accordance with the results by Ghirardello et al. [20]. Genetic analysis confirmed that the hazelnuts had the genetic profile of the cultivar "Tonda Gentile delle Langhe" at all analyzed loci (CaT-B107: 136,154; CaT-B501: 130,130; CaT-B502: 187,191; CaT-B504: 173,185; CaT-B505: 116,128; CaT-B507: 186,192; CaT-B508: 148,164; CaC-B028: 257,263; alleles are expressed in base pairs).

\subsection{Clinical Trial}

Of the 30 initial participants enrolled in the study, 24 subjects were eligible for the study design. 3 person have renounced to participate during the first phase, and 3 did not meet the inclusion criteria: one of them measured a BMI less than 19, one had diabetes mellitus and one had a previous history of ischemic heart disease. The 24 individuals followed a standard intervention without hazelnut for 4 weeks, and after 3 weeks of washout thy followed a standard intervention with $40 \mathrm{~g} / \mathrm{d}$ of hazelnuts. Figure 2 show the study design according to the CONSORT flow diagram. During the intervention phase was assessed compliance of participants, via a recording day-by-day for the evaluation of the acceptance of hazelnuts. The degree of compliance was high in both groups but was $99.4 \%$ in group with hazelnuts, $94.6 \%$ in the group without hazelnuts ( $p=0.002)$. A comparison between two nutritional interventions show a reduction of atherogenic index (AI) and thrombogenic index (TI) when consuming hazelnuts $(\mathrm{p} \leq$ 0.05 ); the nutritional value of macrontrient intake increased after the consumption standard diet plus $40 \mathrm{~g}$ of hazelnuts, as shown in Table 1. At baseline total sample showed a mean age of 31.04 years ( \pm 5.88$)$, a height of $169.57 \mathrm{~cm}( \pm 10.97)$ and an average weight of $66.15 \mathrm{~kg}( \pm 12.24)$. It was detected an average BMI of $22.9 \mathrm{Kg} / \mathrm{m}^{2}( \pm 2.6)$.

With regard to the subdivision of the sample based on obesity, according to the classification of BMI there are not obese subjects, but only about $25 \%$ of overweight subjects. Table 2 shows the nutritional status evaluation before and after hazelnut's supplementation. The only anthropometric value shows a significant change is the hip circumference ( $\mathrm{p} \leq 0.05)$.

After hazelnuts implementation there is a variation of the total body water $(\mathrm{p}=0.007)$, which increases, as well as the extra cellular water $(p=0.009)$. There is a decrease in fat mass $(\mathrm{p}=0.01)$, and an increase in lean mass $(\mathrm{p}=$ 0.01 ). To obtain a comprehensive picture of the transcriptional changes related to a putative positive effects of daily hazelnuts assumption, we analyzed the changes in the gene expression profiles of a total of 84 genes involved in the oxidative stress pathway as shown in Figure 1. After data normalization, considering an absolute fold change at least equal to \pm 1.5 (absolute $F C \geq \pm 1.5$ ) and a p-value $\leq 0.05$ we found: 6 genes up-regulated (BNIP3, GPX2, GSR, HSPA1A, TTN, TXNRD1) and 5 genes down-regulated (CCL5, KRT1, MBL2, PRDX6, SOD1) as shown in Figure 3. The values of oxidized LDL show a significant decrease $(p \leq 0.005)$ after $S D \pm 40 \mathrm{~g} / \mathrm{d}$ of hazelnuts as shown in Figure 4.

\section{Discussion}

Studies focusing on the function of food compounds on inflammatory response and oxidative stress have opened a new window on chronic non-communicable diseases (CNCD) prevention. CNCD are non-infectious and non-transmissible among people diseases, of long duration and slow progression, including obesity, car diovascular diseases, diabetes, chronic kidney disease, osteoporosis, sarcopenia, Alzheimer's disease, and many cancers. According to WHO 2011 report [21], the $63 \%$ of deaths occurred in the world during 2008 were due to 

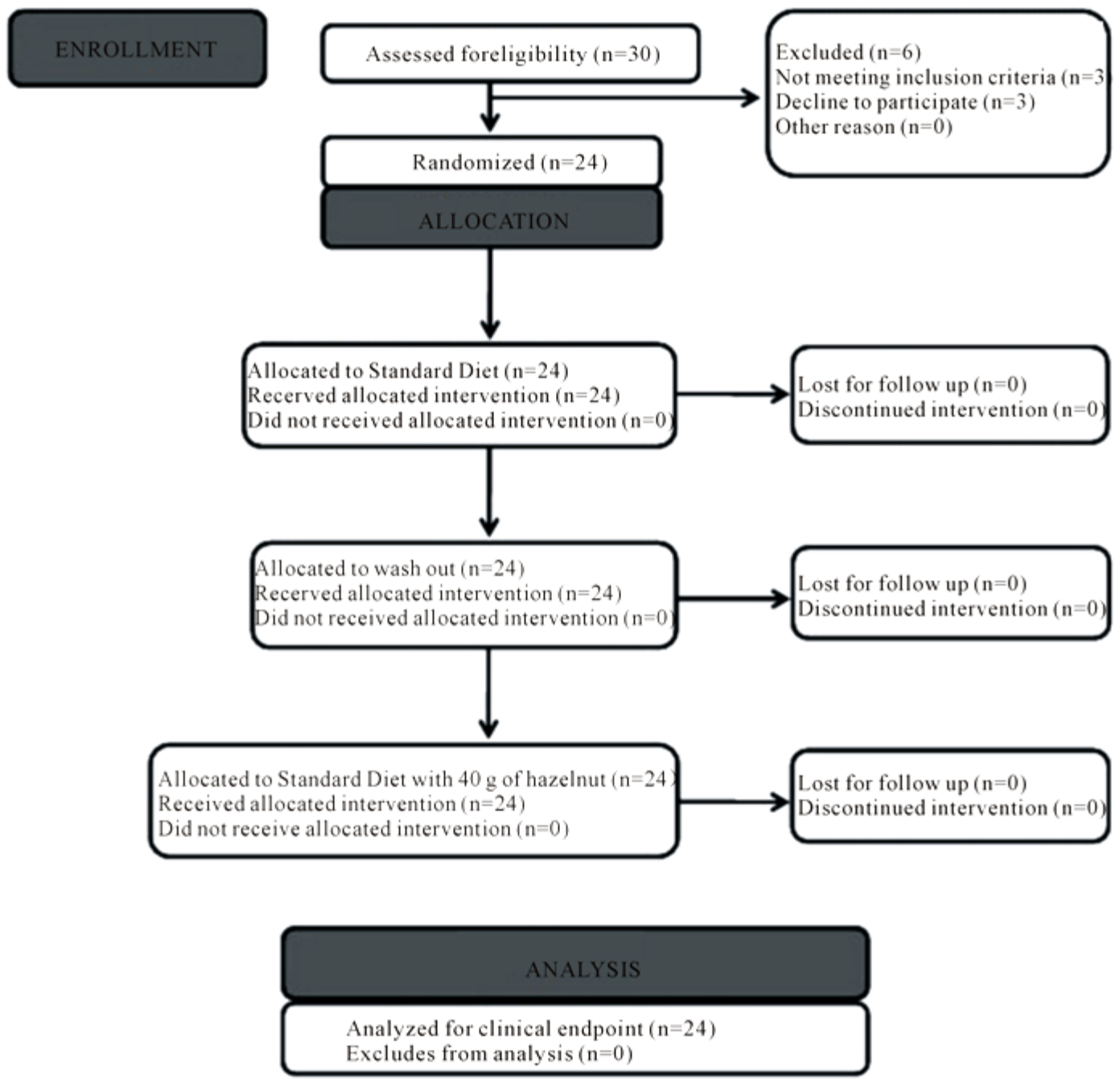

Figure 2. Human oxidative stress pathway. Different levels of up and down regulation of the 84 genes analyzed and involved in the human oxidative stress.

Table 2. Nutritional status evaluation after Standard Diet and Standard Diet plus 40 g/die of hazelnut supplementation.

\begin{tabular}{cccc}
\hline & $\mathbf{M} \pm$ SD & $\mathbf{M} \pm$ SD & p-value \\
\hline & Standard Diet & $\begin{array}{c}\text { Standard Diet } \\
\text { with hazelnuts }\end{array}$ & \\
\hline Weight (kg) & $67.8 \pm 11.35$ & $66.84 \pm 10.39$ & $\mathbf{b}$ \\
Waist (cm) & $76.44 \pm 5.12$ & $76.43 \pm 6.51$ & $\mathbf{b}$ \\
Hips (cm) & $97.5 \pm 7.49$ & $99.76 \pm 10.56$ & $\mathbf{a}$ \\
TBW (l) & $36.5 \pm 6.57$ & $38.08 \pm 6.87$ & $\mathbf{a}$ \\
ECW (l) & $15.66 \pm 2.38$ & $16.93 \pm 2.76$ & $\mathbf{a}$ \\
ICW (l) & $20.83 \pm 4.48$ & $21.15 \pm 4.38$ & $\mathbf{b}$ \\
FM (Kg) & $16.93 \pm 3.21$ & $14.83 \pm 3.17$ & $\mathbf{a}$ \\
MM kg & $34.56 \pm 7.34$ & $35.07 \pm 7.21$ & $\mathbf{a}$ \\
LDL-ox & $40.38 \pm 6.02$ & $36.99 \pm 5.45$ & $\mathbf{a}$ \\
\hline
\end{tabular}

$\mathrm{TBW}^{\mathrm{a}}=$ Total Body Water; ECW ${ }^{\mathrm{a}}=$ Extra Cellular Water; ICW $^{\mathrm{b}}=$ Intracellular Water; $\mathrm{FM}^{\mathrm{a}}=$ Fat Mass; $\mathrm{MM}^{\mathrm{a}}=$ Lean Mass. Values are expressed as mean \pm standard. The significant values are expressed as: (a) $\mathrm{p}<0.05$ and (b) $\mathrm{p}>0.05$. chronic non-communicable diseases, principally cardiovascular diseases (48\%), cancer (21\%) chronic obstructive pulmonary disease (COPD) (4.2 million). Diabetes caused an additional 1.3 million deaths. The prevalence of CNCDs is rising rapidly and WHO projections show that NCD deaths are projected to increase by $15 \%$ globally between 2010 and 2020 (to 44 million deaths). The effects of diet compounds on metabolic pathways related diabetes, cardiovascular diseases, and other CNCD is currently under investigation and it is leading the traditional nutritional counselling to a more complex approach based on gene expression modulation by food. Considering together these "food related" pathologies, the burden of disease in western countries is impressive [22]. The role of diet nutritional quality has been demonstrated by several scientific studies that examined the relationship between diet, overweightness, obesity and cancer, cardiovascular disease and diabetes [23]. The Hazard Analysis and Critical Control Point (HACCP) (Regulation (EC) $\mathrm{N}^{\circ}$ 


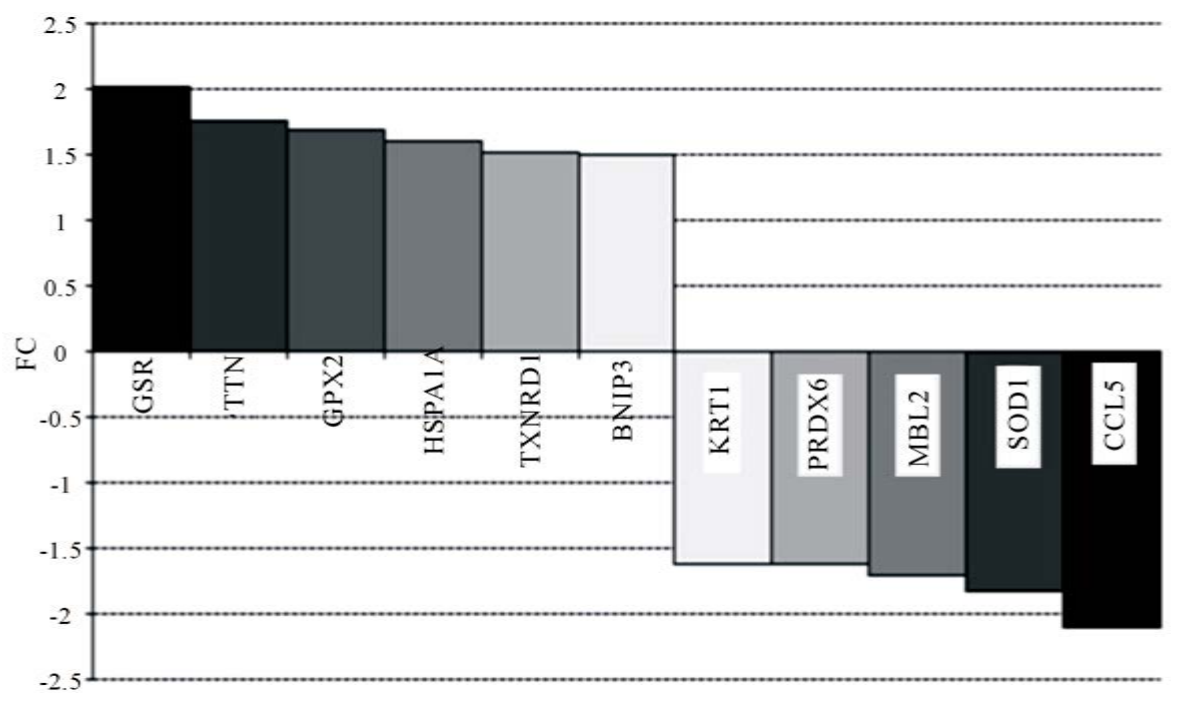

Figure 3. Different significant level of genes expression after 40 g/die hazelnut's supplementation. The up-regulated genes were: BNIP3 (BCL2/adenovirus E1B 19 kDa interacting protein 3; NM_004052), GPX2 (glutathione peroxidase 2; NM_002083), GSR (glutathione reductase; NM_000637), HSPA1A (Heat shock 70 kDa protein 1A; NM_005345) TTN (titin; NM_003319) and TXNRD1 (thioredoxin reductase 1; NM_003330). The down-regulated genes were: CCL5 (chemokine (C-C motif) ligand 5; NM_002985) KRT1 (keratin; NM_006121), MBL2 (mannose-binding lectin (protein C) 2 soluble; NM_000242), PRDX6 (peroxiredoxine 6; NM_004905), SOD1 (superxide dismutase 1, soluble; NM_000454). The significant values are expressed as p $\leq 0.05$.

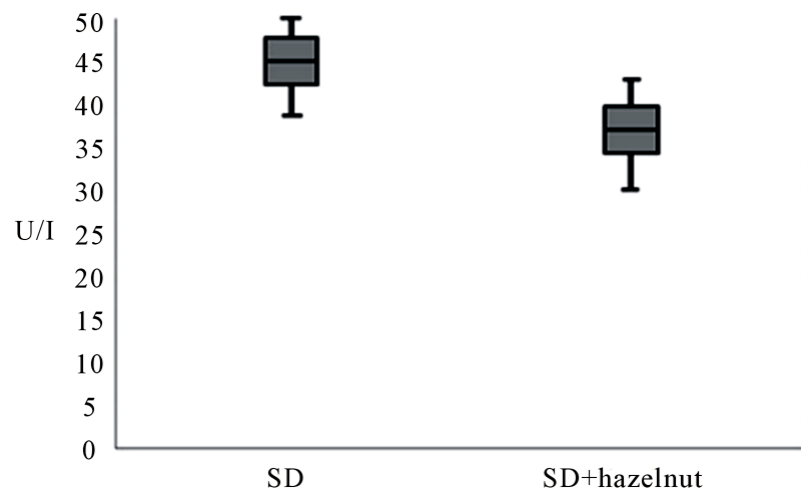

Figure 4. Effect of $40 \mathrm{~g} /$ die of hazelnuts on LDL-ox. The values of oxidized LDL show a significant decrease ( $p \leq$ 0.005 ) with the combination of hazelnuts. The value found with the standard meal in association with hazelnuts was $36.99 \pm 5.45 \mathrm{U} / \mathrm{l}(\min 28.58$ - $\max 47.75)$, meanwhile the consumption of the meal without hazelnuts showed an average value of $40.38 \pm 6.02(\mathrm{~min} 33.95-\min 50.58)$.

852/2004) system is the internationally agreed approach to food safety control; in the prevention of foodborne illnesses the "from farm to fork" food chain the official checks performed by the competent authorities involved in assuring food quality may be not sufficient, since it is necessary to follow the nutrient throughout the chain that goes "from farm to the consumer". In order to implement HACCP, we performed a new process not only for food safety, but also for food quality. The NACCP is based on the principle that food has to be considered in a complete manner, targeting both safety and nutritional aspects, since increased awareness in both sectors generally encourages healthy eating and good habits, and prevents acute and chronic diseases [4]. This double intervention is innovative and no other similar processes have been done in Italy or worldwide. We applied the NACCP process to hazelnut food chain, using TPC and TAC as biomarker for the traceability of nutritional quality, in order to verify the effects of hazelnut consumption. Hazelnuts have a number of cardioprotective compounds including vitamin E (alpha-tocopherol isomer), phytosterols, vitamin B6, folate, L-arginine, polyphenols and fiber. In addition, it is the second richest source of Monounsaturated Fatty Acids (MUFAs) among nuts. It contains approximately 82\% - 83\% MUFAs, mainly oleic acid (18:1) and less than 7.7\% - 8\% saturated fatty acids (SFA) [24]. Hazelnuts can be considered as a good source of phenolic compounds. In the hazelnut sample used for the study the TPC was higher respect to TPC values found in fruits of major species such as apple, pear, nectarine, kiwifruit and in the kernel of other important nut species such as almond and nut pine, but lower respect to berry fruits and walnut, known to be excellent sources of bioactive compounds [25]. Contrary to most fruit species, hazelnut can be stored in appropriate conditions for over a year maintaining unaltered the sensory, physical and nutraceutical characteristics [20]. This makes the product easily available during all the year both for the direct consumption and for the food industry to be used in confectionery, increasing the consumption sources. In raw hazelnut, as in other nuts with the exception of walnut, the pellicle contains more than 
$50 \%$ of the total antioxidants and the cultivation management, storage conditions (in shell or shelled, temperature and atmosphere conditions) and genotype affects the content of total antioxidants. For this reason it is important to assess the quality and origin of the product consumed to optimized the diet and the effect of the hazelnut consumption on human health. The hazelnut cultivar used in this study was confirmed to be "Tonda Gentile delle Langhe", recently renamed "Tonda Gentile Trilobata" and protected under the PGI "Nocciola Piemonte"; it is particularly appreciated for its qualitative parameters such as the ease of pellicle removal, the good shelf life and the excellent flavour after roasting. In accordance with the results of Alasalvar et al. [26], in our analysis the most abundant minerals in nuts are potassium, calcium, magnesium, selenium, iron and zinc. Pollutants were also analyzed that can be harmful to human health. The levels of lead [Reg EU 1881/2006] and aflatoxins [Reg EU 165/2010] found within acceptable limits. Many studies [27] have investigated the effects of diets containing nuts on marker of endothelial function or inflammation, but to our knowledge there are no studies that analyze the effect of the nutrigenomic hazelnut on human beings. When LDL is oxidized, it is even more atherogenic and plays an important role in the pathogenesis of atherosclerosis [28]. Monousaturated fatty acids have been reported to have hypolipidemic effects [29]. In this study, we found a significant lowering of LDL oxidized proteins, in association with the consumption of $40 \mathrm{~g} / \mathrm{d}$ of hazelnuts. As reported by Yücesan et al. [30], $\alpha$-tocopherol is lipid soluble and therefore, able to travel within the LDL particle and indeed costitutes the main antioxidant species directly coating the LDL particle surface. It can inhibit radical chain propagation by scavenging highly reactive lipid peroxyl and alkoxyl radicals, which promote the propagation of the chain reaction of lipid peroxidation [31]. It may be suggested that high MUFA and tocopherol content of a hazelnut-enriched diet could be responsible for decrease in the susceptibility of LDL to oxidation. Particularly significant is the change in body water, and extracellular total hip circumference $(\mathrm{p} \leq 0.05)$ of consumer after standard diet with $40 \mathrm{~g} /$ die of hazelnut. It should be noted, also, one significant deviation of the value of hip circumference between the initial phase of fasting and the one immediately after the antioxidant diet period ( $\mathrm{p} \leq 0.05)$. Introduction in the diet of some specific nutrient could modulate the expression profiles of specific genes involved in the antioxidant defense mechanism. Peripheral blood mononuclear cells (PBMCs) were used for gene expression studies, because they can be easily collected in contrast to other tissues [32]. However, gene modulation in PBMCs has not sufficiently been investigated in the context of human oxidative stress, inflammation, CHD, CAD and diet. To determine whether hazelnut consumption has an antioxidant effect on gene expression profile, we conducted a qRT-PCR array of 84 genes related to antioxidant defenses and oxidative stress pathway in human PBMC before and after 40 days of $40 \mathrm{~g} / \mathrm{d}$ hazelnuts supplementation in a standardized diet. After data normalization, we found 11 statistically significant genes differentially expressed (p $\leq 0.005$ ). Each of them has a unique function in fighting oxidative stress and they act synergistically to combat the oxidative stress implicated for example in atherosclerosis. It was interesting to note that some of the up-regulated genes are antioxidant genes; between the antioxidant enzymes that we found up-regulated after hazelnut diet intervention we have GPX2, GSR and HSPA1A. GPX2 gene is a member of the glutathione peroxidase family and encodes a selenium-dependent glutathione peroxidase that is one of two isoenzymes responsible for the majority of the glutathione-dependent hydrogen peroxide-reducing activity in the epithelium of the gastrointestinal tract. Our finding of an up-regulation of GPX2 gene after hazelnuts consumption may suggest that the antioxidant effect of hazelnut biochemical compounds could be related to an increase of this antioxidant enzyme at transcription level, indicating a protective effect against inflamation, oxidative stress and atherogenesis. GSR is a gene encoding a member of the class-I pyridine nucleotide-disulfide oxidoreductase family. It is a central enzyme of cellular antioxidant defense and reduces glutathione disulfide to the sulfhydryl form, glutathione, which is an important cellular antioxidant. In a recent paper [33] evaluating the oxidative stress (OS) status in subjects with different cardiovascular risk factors, the antioxidant activity of cytoplasmic enzymes was reduced. In our work the transcription levels of GSR were increased after hazelnut consumption ( $p \leq 0.05$ ), suggesting a protective role against oxidative stress and atherogenic process. Our results could be in part supported by the recent work of Wu X. et al. [34,35] in which they found that an up-regulation of GSR gene in mice with diet enriched of blueberry indicated a protective role of these fruits against oxidative stress. This result could be easily compared with our result in which we found an up-regulation of GSR in subjects with a diet enriched of hazelnuts. TXNRD1 is another antioxidant gene that we found up-regulated after hazelnuts introduction in the diet. This gene encoded a protein that regenerates reduced thioredoxin, which serves as reducing equivalent, and may also directly reduce lipid hydroperoxides [36]. Moreover, we found that some of the downregulated genes CCL5, KRT1, MBL2 are pro-oxidant genes. CCL5 gene is one of several chemokine genes clustered on the q-arm of chromosome 17. In Yin-Ling Lin et al. [36,37] paper, the authors suggested that the antioxidant used in their work effectively suppressed CCL5 mRNA expression levels, 
indicating that oxidant may be involved in the induction of the CCL5 gene expression by dengue-2-virus infection. In our work we found that the transcription levels of this genes were decreased $(\mathrm{p} \leq 0.05)$ after hazelnut consumption. A particular trend about the gene expression was found for 2 genes: SOD1 which was an antioxidant enzyme that in our analysis was found down-regulated after hazelnut consumption and HSPA1A is a stress protein that is significantly induced by oxidative stress [38] which could be considered a pro-oxidant factor that was found up-regulated in our work. These 2 genes displayed a trend that was contrary to what we could expect. We found that $S O D 1$, which is an antioxidant gene, was down-regulated $(\mathrm{p} \leq 0.05)$ and $H S P A 1 A$ which is a prooxidant gene result up-regulated $(\mathrm{p} \leq 0.05)$ respectively. SOD1 is the major cellular defense enzyme against superoxides in vascular cells. This gene encodes a protein that binds copper and zinc ions and is one of two isozymes responsible for destroying free superoxide radicals in the body. The encoded isozyme is a soluble cytoplasmic protein, acting as a homodimer to convert naturally occuring but harmful superoxide radicals to molecular oxygen and hydrogen peroxide [39]. Inducible HSP genes can be up-regulated by a wide range of cellular stresses. There is a strong evidence that the induction of HSPs coincides with the acquisition of tolerance to stress, which could otherwise lead to cell death. In our work we found that the gene expression levels of these two genes (KRT1 and MBL2) were down-regulated after the daily hazelnut consumption, suggesting that probably there was a protective effect against the oxidative stress mediated by hazelnut functional biochemical compounds. Although it is acceptable for genomic studies a numerousity of 8 to 25 subjects, the data will be confirmed on a larger number of subjects. Furthermore, it will be necessary to perform a follow up after 1, 3, 6 months to assess the persistence of the benefits on levels of LDL oxidation.

\section{Conclusion}

In conclusion, the nutritional quality of hazelnuts, identified by TPC and TAC is in a certain way transferred to the consumer, as demonstrated by the results of gene expression and LDL oxidation, giving to diet the health qualities. This results support that the hypothesis NACCP process could be applied to obtain significant benefits in terms of primary prevention and contributing to the amelioration of food management at the consumer level. Moreover, it may be applied in agreement with Article 13.1 (EC) Regulation NO. 1924/2006 to nutrition and health claims referring to the role of a nutrient or substance on: growth, development and body function; psychological and behavioral aspects.

\section{Acknowledgements}

The study will be conducted in accordance with the Declaration of Helsinki, and approved by the Committee of the Ministerodelle Politiche Alimentari e Forestali (MIPAAF), Italy, approved by DM 06/12/2011 No. prot. 32064.

\section{REFERENCES}

[1] S. Lakshmana, T. N. K. Suriya Prakash, C. Dinesh Kumar, S. Suresh Kumar and T. Ragavendran, "Nutraceuticals: A Review,” Elixir Pharmacy, Vol. 46, 2012, pp. 8372-8377.

[2] A. Demirbas, "Phenolics from Hazelnut Kernels by Supercritical Methanol Extraction,” Energy Sources Part A, Vol. 29, No. 9, 2007, pp. 791-797.

[3] I. Oliveira, A. Sousa, J. Morais, I. C. F. R. Ferreira, A. Bento, L. Estevinho and J. A. Pereira, "Chemical Composition, and Antioxidant and Antimicrobial Activities of Three Hazelnut (Corylusavellana L.) Cultivars," Food and Chemical Toxicology, Vol. 46, No. 5, 2008, pp. 1801-1807. http://dx.doi.org/10.1016/j.fct.2008.01.026

[4] M. L. Colombo, A. Manzo, S. Dalfà, L. Pistelli, L. Di Renzo, "La Filiera Delle Piante Officinali. Piano di Settore Piante Officinali. Ministero Politiche Agrarie Alimentari e Forestali," The Supply Chain of Medicinal Plants, Ministry of Agriculture, Food and Forestry, UniversItalia, Roma, 2013.

[5] S. Pritam Sukhija and D. L. Palmquist, "Rapid Method for Determination of Total Fatty Acid Content and Composition of Feedstuffs and Feces," Journal of Agriculture and Food Chemistry, Vol. 36, No. 6, 1988, pp. 1202-1206. http://dx.doi.org/10.1021/jf00084a019

[6] Z. M. Rittersma, "Recent Achievements in Miniaturised Humidity Sensors-A Review of Transduction Techniques," Sensors and Actuators A: Physical, Vol. 96, No. 2-3, 2002, pp. 196-210.

[7] K. Slinkard and V. L. Singleton, "Total Phenol Analyses: Automation and Comparison with Manual Methods," American Journal of Enology and Viticulture, Vol. 28, No. 1, 1977, pp. 49-55.

[8] I. F. F. Benzie and J. J. Strain, "The Ferric Reducing Ability of Plasma (FRAP) as a Measure of "Antioxidant Power': The FRAP Assay,” Analytical Biochemistry, Vol. 239, No. 1, 1996, pp. 70-76. http://dx.doi.org/10.1006/abio.1996.0292

[9] N. Pellegrini, M. Serafini, B. Colombi, D. Del Rio, S. Salvatore, M. Bianchi and F. Brighenti, "Total Antioxidant Capacity of Plant Foods, Beverages and Oils Consumed in Italy Assessed by Three Different in Vitro Assays,” Journal of Nutrition, Vol. 133, No. 9, 2003, pp. 28122819.

[10] J. J. Doyle and J. L. Doyle, “A Rapid DNA Isolation Procedure for Small Quantities of Fresh Leaf Tissue,” Phytochemical Bulletin, Vol. 19, No. 1, 1987, pp. 11-15.

[11] P. Boccacci, A. Akkak, N. V. Bassil, S. A. Mehlenbacher and R. Botta, "Characterization and Evaluation of Microsatellite Loci in European Hazelnut (Corylusavellana 
L.) and Their Transferability to Other Corylus Species," Molecular Ecology Notes, Vol. 5, No. 4, 2005, pp. 934937. http://dx.doi.org/10.1111/j.1471-8286.2005.01121.x

[12] N. V. Bassil, R. Botta and S. A. Mehlenbacher, "Microsatellite Markers in Hazelnut: Isolation, Characterization, and Cross-Species Amplification," Journal of the American Society for Horticultural Science, Vol. 130, No. 4, 2005, pp. 543-549.

[13] P. Boccacci, R. Botta and M. Rovira, "Genetic Diversity of Hazelnut (Corylusavellana L.) Germplasm in Northeastern Spain,” Hort Science, Vol. 43, No. 3, 2008, pp. 667-672.

[14] T. G. Lohman, A. F. Roche and R. Martorell, "Anthropometric Standardization Reference Manual," Human Kinetics, Champaign, 1998.

[15] L. Di Renzo, V. Del Gobbo, M. Bigioni, et al., "Body Composition Analyses in Normal Weight Obese Women," European Review for Medical and Pharmacological Sciences, Vol. 10, No. 4, 2006, pp. 191-196.

[16] A. De Lorenzo, A. Andreoli, J. Matthie and P. Withers, "Predicting Body Cell Mass with Bioimpedance by Using Theoretical Methods: A Technological Review,” Journal of Applied Physiology, Vol. 82, No. 5, 1997, pp. 15421558.

[17] A. De Lorenzo, A. Noce, M. Bigioni, V. Calabrese, D. G. Della Rocca, N. Di Daniele, C. Tozzo and L. Di Renzo, "The Effects of Italian Mediterranean Organic Diet (IMOD) on Health Status," Current Pharmaceutical Design, Vol. 16, No. 7, 2010, pp. 814-824. http://dx.doi.org/10.2174/138161210790883561

[18] N. Di Daniele, L. Petramala, L. Di Renzo, F. Sarlo, D. G. Della Rocca, M. Rizzo, V. Fondacaro, L. Iacopino, C. J. Pepine and A. De Lorenzo, "Body Composition Changes and Cardiometabolic Benefits of a Balanced Italian Mediterranean Diet in Obese Patients with Metabolic Syndrome," Acta Diabetologica, Vol. 50, No. 3, 2013, pp. 409-416. http://dx.doi.org/10.1007/s00592-012-0445-7

[19] K. J. Livak and T. D. Schmittgen, “Analysis of Relative Gene Expression Data Using Real-Time Quantitative PCR and the $2^{-\Delta \Delta \mathrm{Ct}}$ Method,” Methods, Vol. 25, No. 4, 2001, pp. 402-408. http://dx.doi.org/10.1006/meth.2001.1262

[20] D. Ghirardello, C. Contessa, N. Valentini, G. Zeppa, L. Rolle, V. Gerbi and R. Botta, "Effect of Storage Conditions on Chemical and Physical Characteristics of Hazelnut (Corylusavellana L.)," Postharvest Biology and Technology, Vol. 81, 2013, pp. 37-43. http://dx.doi.org/10.1016/j.postharvbio.2013.02.014

[21] WHO, "Report Global Status Report on Non-Communicable Disease,” WHO, Geneva, 2010

[22] A. K. Kant, "Dietary Patterns: Biomarkers and Chronic Disease Risk," Applied Physiology, Nutrition, and Metabolism, Vol. 35, No. 2, 2010, pp. 199-206.

[23] C. Alasalvar, F. Shaidi and K. R. Cadwaller, "Comparison of Natural and Roasted Turkish Tombul Hazelnut (Corylusavellana L.) Volatiles and Flavor by DHA/GC/ MS and Descriptive Sensory Analysis,” Journal of Agricultural and Food Chemistry, Vol. 51, No. 17, 2003, pp. 5067-5072. http://dx.doi.org/10.1021/jf0300846
[24] C. Contessa, M. G. Mellano, G. L. Beccaro, A. Giusiano and R. Botta, "Total Antioxidant Capacity and Total Phenolic and Anthocyanin Contents in Fruit Species Grown in Northwest Italy," Scientia Horticulturae, Vol. 160, 2013, pp. 351-357. http://dx.doi.org/10.1016/j.scienta.2013.06.019

[25] R. Blomhoff, M. H. Carlsen, L. F. Andersen and D. R. Jacobs, "Health Benefits of Nuts: Potential Role of Antioxidant," British Journal of Nutrition, Vol. 96, No. 2, 2006, pp. 52-60. http://dx.doi.org/10.1017/BJN20061864

[26] C. Alasalvar, F. Shahidi, C. M. Liyanapathirana and T. Ohshima, "Turkish Tombul Hazelnut (Corylusavellana L.). 1. Compositional Characteristics," Journal of Agricultural and Food Chemistry, Vol. 51, No. 13, 2003, pp. 3790-3796. http://dx.doi.org/10.1021/jf0212385

[27] S. M. Mercanligil, P. Arslan, C. Alasalvar, E. Okut, E. Akgul and A. Pinar, "Effects of Hazelnut-Enriched Diet on Plasma Cholesterol and Lipoprotein Profiles in Hypercholesterolemic Adult Men," European Journal of Clinical Nutrition, Vol. 61, No. 2, 2006, pp. 1-9.

[28] R. Ross. “Atherosclerosis-An Inflammatory Disease," The New England Journal of Medicine, Vol. 340, No. 2, 1999, pp. 115-126. http://dx.doi.org/10.1056/NEJM199901143400207

[29] G. S. Hotamisligil, "Inflammation and Metabolic Disorder,” Nature, Vol. 444, No. 7121, 2006, pp. 860-867. http://dx.doi.org/10.1038/nature05485

[30] F. B. Yücesan, A. Orem, V. B. Kural, C. Orem and I. Turam, "Hazelnut Consumption Decrease the Susceptibility of LDL to Oxidation, Plasma Oxidazed LDL Level and Increase the Ratio of Large/Small LDL in Normolipidemic Healthy Subjects,” Anadolu Kardiyoloji Dergisi, Vol. 10, No. 1, 2010, pp. 28-35.

[31] V. D. De Mello, M. Kolehmainen, U. Schwab, U. Mager, D. E. Laaksonen, U. L. Pulkkinen, et al., "Effect of Weight Loss on Cytokine Messenger RNA Expression in Peripheral Blood Mononuclear Cells of Obese Subjects with the Metabolic Syndrome,” Metabolism, Vol. 57, No. 2, 2008, pp. 192-199.

http://dx.doi.org/10.1016/j.metabol.2007.08.024

[32] C. Berndt, C. H. Lillig and A. Holmgren, "Thiol-Based Mechanisms of the Thioredoxin and Glutaredoxin Systems: Implications for Diseases in the Cardiovascular System," American Journal of Physiology-Heart and Circulatory Physiology, Vol. 292, No. 3, 2007, pp. H1227H1236. http://dx.doi.org/10.1152/ajpheart.01162.2006

[33] M. L. Mansego, J. Redon, S. Martinez-Hervas, J. T. Real, F. Martinez, S. Blesa, et al., "Different Impacts of Cardiovascular Risk Factors on Oxidative Stress,” International Journal of Molecular Sciences, Vol. 12, No. 9, 2011, pp. 6146-6163. http://dx.doi.org/10.3390/ijms12096146

[34] X. Wu, J. Kang, C. Xie, R. Burris, M. E. Ferguson, T. M. Badger and S. Nagarajan, "Dietary Blueberries Attenuate Atherosclerosis in Apolipoprotein E-Deficient Mice by Upregulating Antioxidant Enzyme Expression,” Journal of Nutrition, Vol. 140, No. 9, 2010, pp. 1628-1632.

[35] S. Wassmann, K. Wassmann and G. Nickenig, "Modulation of Oxidant and Antioxidant Enzyme Expression and Function in Vascular Cells,” Hypertension, Vol. 44, No. 4, 
2004, pp. 381-386.

http://dx.doi.org/10.1161/01.HYP.0000142232.29764.a7

[36] Y. L. Lin, C. C. Liu, J. I. Chuang, H. Y. Lei, T. M. Yeh, Y. S. Lin, Y. H. Huang and H. S. Liu, "Involvement of Oxidative Stress, NF-IL-6, and RANTES Expression in Dengue-2-Virus-Infected Human Liver Cells,” Virology, Vol. 276, No. 1, 2000, pp. 114-126.

[37] Y. Zheng, V. Le, Z. Cheng, S. Xie, H. Li, J. T. Jianwen Liu, "Development of Rapid and Highly Sensitive HSPA1A Promoter-Driven Luciferase Reporter System for Assessing Oxidative Stress Associated with Low-
Dose Photodynamic Therapy," Cell stress and Chaperones, Vol. 18, No. 2, 2013, pp. 203-213.

[38] H. Kawamata and G. Manfredi, "Import, Maturation, and Function of SOD1 and Its Copper Chaperone CCS in the Mitochondrial Intermembrane Space,” Antioxidants \& Redox Signaling, Vol. 13, No. 9, 2010, pp. 1375-1384. http://dx.doi.org/10.1089/ars.2010.3212

[39] T. H. Pohlman and J. M. Harlan, "Adaptive Responses of the Endothelium to Stress,” Journal of Surgical Research, Vol. 89, No. 1, 2000, pp. 85-119. http://dx.doi.org/10.1006/jsre.1999.5801

\section{Abbreviations}

TGL: Tonda Gentile delle Langhe;

TPC: Total Phenolic Content;

TAC: Total Antioxidant Capacity;

FRAP: Ferric Reducing Antioxidant Power;

GAE: Gallic Acid Equivalents;

PGI: Protected Geographical Indication;

SSR: Simple Sequence Repeats;

PCR: Polymerase Chain Reaction 